\title{
THE UIS MODEL FOR ONLINE SUCCESS
}

\author{
Bill Bloemer, Ph.D. \\ Research Associate, Center for Online Learning, Research and Service \\ University Of Illinois - Springfield
}

\begin{abstract}
This case study describes the philosophy underlying the delivery of online programs and courses at the University of Illinois - Springfield. The strategies used to implement the UIS model and the measures used to validate its success are outlined. These factors are reviewed in the context of the Sloan-C Five Pillars for quality learning environments.
\end{abstract}

\section{KEYWORDS}

Retention, Student Success, Course Completion, Strategies, Sloan-C Five Pillars, UIS Model, COLRS

\section{INTRODUCTION}

The University of Illinois-Springfield has been a national leader in the development of online baccalaureate degree completion and graduate programs. This case study describes the UIS model for the delivery of online courses and degrees. The measures that we have used to confirm programmatic success are briefly described, as are some of the techniques we have used to help students succeed. Course completion rates in online courses at UIS have consistently exceeded $90 \%$ and remain within $1-2 \%$ of those for traditional on campus offerings. Baccalaureate degree completion and graduate students continue to comprise the majority of online enrollments at UIS.

\section{MISSION AND CONTEXT}

Founded in the capital of Illinois as an upper division and graduate commuter institution in 1973, Sangamon State University joined the University of Illinois system as the University of IllinoisSpringfield in 1995. The institution's original commitment to finding innovative ways to provide access to higher education for the "non-traditional" adult student made it natural for UIS to develop online programs. As the result of faculty initiatives, the first online courses appeared in 1998. The development of the first online programs followed shortly thereafter. With substantial support from the Alfred P. Sloan Foundation, UIS has been steadily developing additional online degree programs since then. Currently the campus offers 8 undergraduate and 8 graduate degrees completely online, as well as several certificates. Majors in these online programs make up about $1 / 4$ of UIS' total enrollment. In recent semesters roughly half of UIS' students have taken at least one online course.

In 2001, UIS became a full four year institution, admitting its first class of traditionally aged, full-time residential freshmen, under the name of the Capital Scholars program. The simultaneous continuing growth of the online programs and the Capital Scholars program make UIS one of the more interesting places in higher education at the moment. The vision statement adopted as part of the institution's 2007 Strategic Plan says: 
"UIS will be a premier small public university offering innovative, high-quality liberal arts education, public affairs activities, and professional programs dedicated to academic excellence, to enriching individual lives, and to making a difference in the world.”

The plan reaffirms the commitment "to reach out to non-traditional students with ... an increasing number of online programs." The plan states also: "UIS' approach to and experience with online undergraduate degree completion programs is an extension of our commitment to serving non-traditional students and is consistent with what would be expected at leading small public liberal arts universities." "We are well positioned to meet the lifelong learning needs of the non-traditional student nationally with our online presence and with our considerable experience on campus in working with non-traditional students.”

\section{DEMOGRAPHICS}

In the fall of 2004, the University of Illinois launched a new enterprise-wide data system. The demographics of our online majors have been carefully followed since then. Even as additional online programs have been added and online enrollments have steadily grown, the fundamental characteristics of our online majors have been very stable. The average age of our online students is close to 35 years. Surprisingly this is true for both undergraduate and graduate students, whose average age rarely differs by as much as one year. By race and gender, UIS' online population is not significantly different from the traditional commuting population. As measured by their mailing addresses, 35-40\% of the online students are outside the state of Illinois. UIS has adopted e-tuition for online majors that is the same for all students regardless of their state of residency. Of those online students who do reside in Illinois, roughly $85 \%$ are outside of Sangamon county (UIS' location). Many of these are located in the major population centers of the state which are well beyond typical commuting distance to campus. The online programs allow UIS to serve a population that would not normally commute to the physical campus.

\section{THE “UIS MODEL”}

From the beginning, the UIS approach to online learning has been defined by fundamental commitments that have come to be described as the "UIS model for online education."

UIS' online programs are identical in all possible ways to the previously existing on-campus offerings, with the obvious difference of the instructional format. The courses are the same as those offered on campus. They have the same requirements, and are offered on the same academic calendar. The assignment of faculty to the online courses is done in the same way that on-campus teaching assignments are made. While UIS as a whole is using an increasing number of adjuncts, courses are usually taught by full-time tenure track faculty whether online or in traditional modes. The processes of faculty governance for the online programs are the same as those used for on campus programs from the department to the Campus Senate level.

Care has been taken to develop the online programs in a way that strengthens the existing on campus offerings without overwhelming them. The number of students admitted to the online programs each year is controlled. The infusion of this new group of majors typically enhances the regional diversity and quality of the student population. The addition of the online student population makes it possible to use existing faculty resources more efficiently. In most cases, the increase in enrollment has justified the addition of faculty lines, enhancing both the depth and breadth of curricular offerings and the range of faculty expertise in the department. 
Significant differences for the online programs do exist in their admissions criteria. Because the online programs draw applicants nationally into programs that have limited capacity, the entrance criteria for the online programs are higher than those for the corresponding on campus program in almost all cases. It is also the case that online courses were initially capped at 20, recognizing the special demands of this instructional format. As programs have gained experience with online learning, some of those caps are being gradually increased, but they still remain lower, in many cases, than the caps for corresponding on campus offerings.

The continuing commitment to providing the same high quality program online that we deliver on the campus defines the UIS model for online education, which is the primary reason for our online retention success.

\section{THE DEFINITION OF "SUCCESS"}

Early measures of retention were derived from comparisons of census and end of term enrollment figures. Comparable data are tracked today. By that definition, a successful student is one who was registered at the time of the tenth day census and who remains registered at the end of the term. Internally, more detailed data is also collected. The students who remain registered are further classified according to whether they earned a transferable passing grade (B or better for graduate, $\mathrm{C}$ or better for undergraduate), a passing grade lower than that, an incomplete, or a failing grade).

For these purposes, our original definition of retention is used. Under that definition (continuing enrollment), retention is online courses has consistently been within one or two percent of that for on campus courses. In both cases the figure has remained in the $90-95 \%$ range. The comparability between online and on campus results is also seen in the more finely detailed categorization mentioned above.

\section{THE SLOAN-C FIVE PILLARS}

The UIS online initiative has developed over the past decade with the generous financial support from the Alfred P. Sloan foundation. We measure our success in terms of the quality framework of the Sloan-C Five Pillars, allowing us to monitor and set goals for continuing improvement of the online initiative.

\section{A. Learning Effectiveness}

To assess the effectiveness of the UIS model, we have looked at all the grades earned over a three year period for both the online and traditional delivery methods. Factors such as the level of the course, the department of origin and the major of the student are well known to influence the grade distribution in a given course. Once a statistical model has been used to factor in those effects, the remaining effect of the online delivery format has been shown to be negligibly small. Within that analysis, though, it is clear that our online majors generally have higher GPA's than their on campus counterparts. The difference is attributed to the more selective admission criteria and the fact that the online students generally fit the label of "mid-career adults." It also appears that the performance of on campus majors who elect to take or are forced into online courses is slightly lower than expected.

Similarly, degree completion rates are also being monitored. In order to implement e-tuition, UIS began carefully identifying online majors by academic year 2005-06. For that reason, final degree completion rates for online programs will not be available for a while yet. Interim review of the baccalaureate degree completion programs indicates, though, that retention and graduation rates are trending at or above the 
historical levels of the corresponding on campus programs in most cases.

Online coordinators, academic support staff assigned to the online programs, have been essential to the effectiveness of the online programs. These are half time appointments, at a minimum. The online coordinator is the face of the institution to students from point of application to graduation. They serve as marketers, advisors, troubleshooters, and coaches throughout the student's academic career. The use of online peer tutors has also proven to be very effective in particularly challenging courses. The Center for Teaching and Learning, which has traditionally provided support services for on campus students, now delivers online tutoring and other academic support to online and on campus students. Technical support is available to all students $24 \times 7$. Each of these measures resulted from continuing attempts to make the online programs more effective.

\section{B. Scale}

The UIS model is not the least expensive option for the implementation of online degree programs. To demonstrate cost effectiveness and assure continuing institutional commitment, proposals for online programs must include a long term budget plan that addresses the continuing viability of the proposed offerings. Using clear targets for the number of students admitted annually and conservative estimates of persistence and completion rates, the anticipated tuition and fees generated must exceed the program's operational costs. This is a standard that not all existing programs could meet. The specific budget expectations are recorded in a memo of understanding that is negotiated among the program, the Dean and the Provost. In almost all cases, the annual admissions targets have been met or exceeded. The realized persistence rates, combined with recent tuition increases have produced revenues that have exceeded original projections. Operational costs, primarily faculty and staff salaries, have not increased over original projections as rapidly. The UIS online programs are now an integral and effective part of the campus offerings.

\section{Access}

The demographics of the online student population, described above show clearly that UIS' online programs are attracting a student population that could not possibly commute to campus for traditional offerings. In recent academic years, UIS has provided access to higher education for students in almost all of the fifty states, most counties in Illinois, and a number of foreign countries. Articulation agreements with institutions across the nation have been critical to our ability to attract students.

\section{Faculty Satisfaction}

When it became apparent that online offerings were growing rapidly, the Campus Senate hosted a series of hearings to address various faculty concerns that inevitably were being voiced. No clearer evidence of faculty satisfaction is needed but to note that by the next year the focus of the Senate's concerns had shifted to making sure that all programs were being given an equal chance to develop online. The demonstrable success of the online offerings and the presence of a new, geographically diverse, and highly qualified student population were in part responsible for the rapid change in faculty attitudes. The infusion of new resources, in otherwise difficult budgetary times, also had an impact. Faculty satisfaction is evident as the number of online programs and their size continues to increase, as does the number of faculty who teach online. Certainly the flexibility afforded by online courses is appealing to many faculty. More than that, though, online teaching has actually helped the careers of faculty who need to be away from campus for an extended period of time or whose teaching is better suited to the online format for various reasons. 
To assure continuing faculty success in the online classroom, the Office of Technology Enhanced Learning (OTEL) provides a variety of support and developmental services for online faculty. In addition to individual consultations, a series of regular faculty seminars and workshops is provided primarily by OTEL and Information Technology Services. The faculty themselves have organized a community of practice to enhance online teaching effectiveness. The Community of Practice for E-Learning (COPE-L) helps faculty from all corners of the campus network to share best practices for online teaching. The role of OTEL is being expanded to foster faculty research into the effectiveness of online teaching and learning. For that reason, the unit has recently been renamed the Center for Online Learning, Research and Service (COLRS) in accordance with the institutional strategic plan.

\section{E. Student Satisfaction}

Student satisfaction with online offerings is evident by many measures, not the least of which is the rapid and continuing growth in online enrollments, roughly half of which comes from on campus students. It is clear, from watching enrollment patterns, that online classes generally fill very quickly and routinely have many more students attempting to register for them than can be served. Examinations of end of term student course evaluations have also been conducted. Since the evaluations are, of course, anonymous, the analysis cannot be as detailed as that of grades earned. It is clear, though, the student's expected grade, the level of the course and the department of origin all influence the resulting evaluations. Once those effects have been accounted for, the effect of the online delivery mode is again negligible. In short, students are voting with their feet. End of course evaluations show that their high level of satisfaction with our courses is not diminished online.

\section{CONCLUSION}

This case study described the philosophy underlying the delivery of online programs and courses at the University of Illinois - Springfield. The factors are reviewed in the context of the Sloan-C Five Pillars for quality learning environments, which have guided programmatic development at UIS. The measures validate the UIS Model for online education.

\section{ABOUT THE AUTHOR}

Bill Bloemer, Ph.D. is a chemist and Dean Emeritus of the College of Liberal Arts and Sciences at UIS. He is currently a research associate in the Center for Online Learning, Research and Service (COLRS) at UIS. 